\title{
EDITORIAL
}

\section{Minimally invasive inguinal hernia repair: back to the future}

\author{
Reparo mínimamente invasivo de la hernia inguinal: volver al futuro \\ Edward L. Felix, MD, FACS \\ General Surgeon, Specialist in Bariatric Surgery, Fresno, California
}

Laparoscopic inguinal hernia repair has come a long way in the last 25 years. We began with very crude instrumentation, but with the knowledge that we had to duplicate the posterior repairs of Nyhus and Stoppa. At first, most surgeons utilized a transperitoneal (TAPP) because the anatomical view was a familiar one. Soon however, many surgeons with advanced laparoscopic skills switched over to a totally extraperitoneal technique (TEP). The techniques have been slow to gain universal popularity, but have finally been accepted in some circles as the gold standard. With the addition of the extended totally extraperitoneal approach (E-TEP) developed by Jorge Daes that allows the MIS approach to be applied to many of the anatomically more difficult hernias and the robotic TAPP (R-TAPP) that seems to shorten the learning curve for new MIS surgeons, the adoption of MIS inguinal hernia repair is now rapidly increasing.

Many surgeons however, have failed to look at the lessons learned during the early development of MIS inguinal hernia repair. There are no shortcuts when utilizing an MIS approach. It does not matter which of the four techniques a surgeon utilizes, they must follow the basic tenants of laparoscopic inguinal hernia repair developed over the last 25 years. The cornerstone of the MIS approach is and always will be the complete dissection of the myopectineal orifice (MPO) and total coverage of all three potential hernia defects, following the steps of the Critical View of the MPO published in Annals of Surgery $^{\mathrm{I}}$. There has been a recent attempt to create shortcuts and to tailor the operation. History shows that previous attempts to do this have only resulted in recurrence due to missed hernias and technical failures. I would hope anyone trying to reinvent this eloquent procedure would first study how we got to where we are today before they try to alter the technique. Most of the new shortcuts and variations in the procedure have been tried and failed in the past. Yes, it is important to always be looking to improve what is considered the standard, but before a change is promoted on You Tube or social media significant data should be collected so that we don't inadvertently undo what has taken so long to perfect.

\section{Reference}

I. Daes J, Felix E. Critical view of the myopectineal orifice. Ann Surg. 20I7;266:eI-e2. doi: Io.IO97/ SLA.0ooooooooooo2I04

Palabras clave: hernia, inguinal; herniorrafia; historia; procedimientos quirúrgicos; curva de aprendizaje. Key words: hernia, ilguinal; herniorrhaphy; history; surgical procedures; learning curve.

Fecha recibido: 05/06/2018 Fecha aceptación: 12/06/2018

Correspondencia: Edward L. Felix, MD, FACS, Advanced Bariatric Center 7060 N Recreation Avenue, Suite 101, Fresno, CA 93720. Citar como: Felix EL. Minimally invasive inguinal hernia repair: back to the future. Rev Colomb Cir. 2018;33:246. https://doi. org/10.30944/20117582.67 